\title{
Now you see it, now you don't- the hidden life of cerebral dural arteriovenous fistulae
}

\author{
Gabriele Brasse • Henrik J. Roth • Dominik Fritzsch • \\ Rainer Scheid
}

Received: 3 November 2008 / Accepted: 20 November 2008 /Published online: 13 December 2008

(C) The Author(s) 2008. This article is published with open access at Springerlink.com

Sir,

We would like to bring to your attention our experience with a 47-year-old female patient who presented acutely with a left temporal haemorrhage for which no cause was identified on CT-angiography (Fig. 1). Four months later, MRI with TOF-MRA was also normal (Fig. 2) but surprisingly, an MRI, a further 4 months later (Fig. 3), was highly suspicious of a DAVF and this diagnosis was confirmed by DSA (Fig. 4). She was scheduled for treatment by embolisation but when DSA was repeated 3 months later, immediately prior to treatment, the DAVF

G. Brasse $\cdot$ R. Scheid $(\bowtie)$

Max Planck Institute for Human Cognitive and Brain Sciences, Stephanstrasse. 1a,

04103 Leipzig, Germany

e-mail: scheid@cbs.mpg.de

G. Brasse $\cdot$ R. Scheid

Day Clinic of Cognitive Neurology, University of Leipzig,

Leipzig, Germany

H. J. Roth

Department of Radiology, MediClin Robert Janker Clinic Bonn, Bonn, Germany

D. Fritzsch

Department of Radiology, University of Leipzig,

Leipzig, Germany was no more. This finding was confirmed on further MRI/ MRA scans.

We concluded that the contradictory imaging findings in our patient most likely reflected a dynamic process of an initial closure, re-opening, and repeat spontaneous closure of a symptomatic DAVF during the follow-up period of 12 months. The results can be regarded reliable, since identical parameters were used for repeat MRI and MRA, and because MRI/MRA findings matched the DSA findings when the procedures were performed in close temporal relationship.

An alternative hypothesis - namely, that there originally might have been a venous congestive bleeding after a thrombosis of a major cortical vein draining into the transverse sinus and a secondary evolvement of a DAVF — seems unlikely since (1) there was an unremarkable initial CTA; (2) in retrospect the patient reported a left-sided pulsatile tinnitus, which had started several months prior to the haemorrhage.

Nevertheless, the possibility that the negative first MRI/ MRA reflects an insufficient sensitivity of the imaging technique must be considered. The potential invisibility of slow flow DAVFs in the TOF modality has been discussed previously; however, the heightened sensitivity of the respective source images has been emphasized $[1,2]$. In our patient, both TOF-MRA and the source images were unremarkable. Missing or insufficient visualization of DAVFs using TOF-MRA in the subacute phase of cerebral haemorrhages is usually attributed to the T1-shortening effect due to haemorrhage or the mass effect of the haemorrhage itself [3]. In our patient, the T1-shortening 


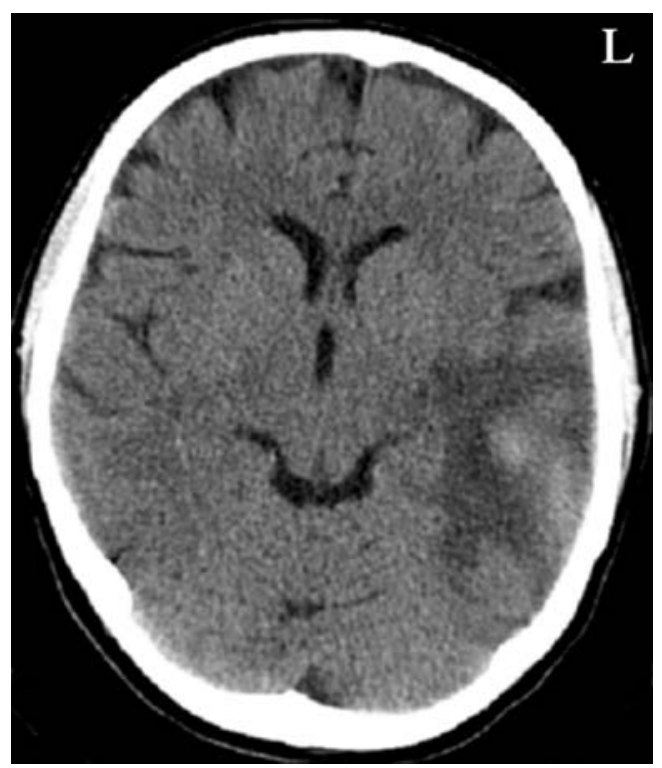

Fig. 1 An axial view section of a cranial computed tomography from the acute phase shows a haemorrhage in the left temporal lobe with a marked perifocal edema

effect was limited to the margins of the resolving haemorrhage, already showing shrinkage due to tissue loss. Secondary vasospasms after subarachnoid haemorrhage that may result in a functionally relevant decrease of flow velocity [4] are also unlikely, considering the 4-month interval between bleeding and the first follow-up in our patient.

There have been anecdotal reports of spontaneous closure of DAVFs [5-7]. However, to the best of our knowledge, there is no report documenting the repeat spontaneous closure and re-opening of a DAVF. The pathophysiology of spontaneous closures of DAVFs is uncertain. Vasospasms of feeding arteries, mass effect and oedema could be the source of a direct compressive effect and consecutive thrombosis. Haemodynamic interactions between sinus and DAVF, reinforcement due to increased intracranial pressure, as well as altered surface properties in the sinus itself have been assumed [5-7]. Whereas partial sinus thrombosis could be a prerequisite for the primary development of a DAVF, complete thrombosis of the sinus might be followed by its closure [5]. In our patient, however, signs or symptoms of intracranial thrombosis were absent.

Our observations demonstrate that DAVFs may not only close spontaneously, but are also liable to re-open. This implies the need for longer radiological follow-up than is currently generally practiced. The appropriateness of radiological tools other than DSA for this purpose needs to be further determined.
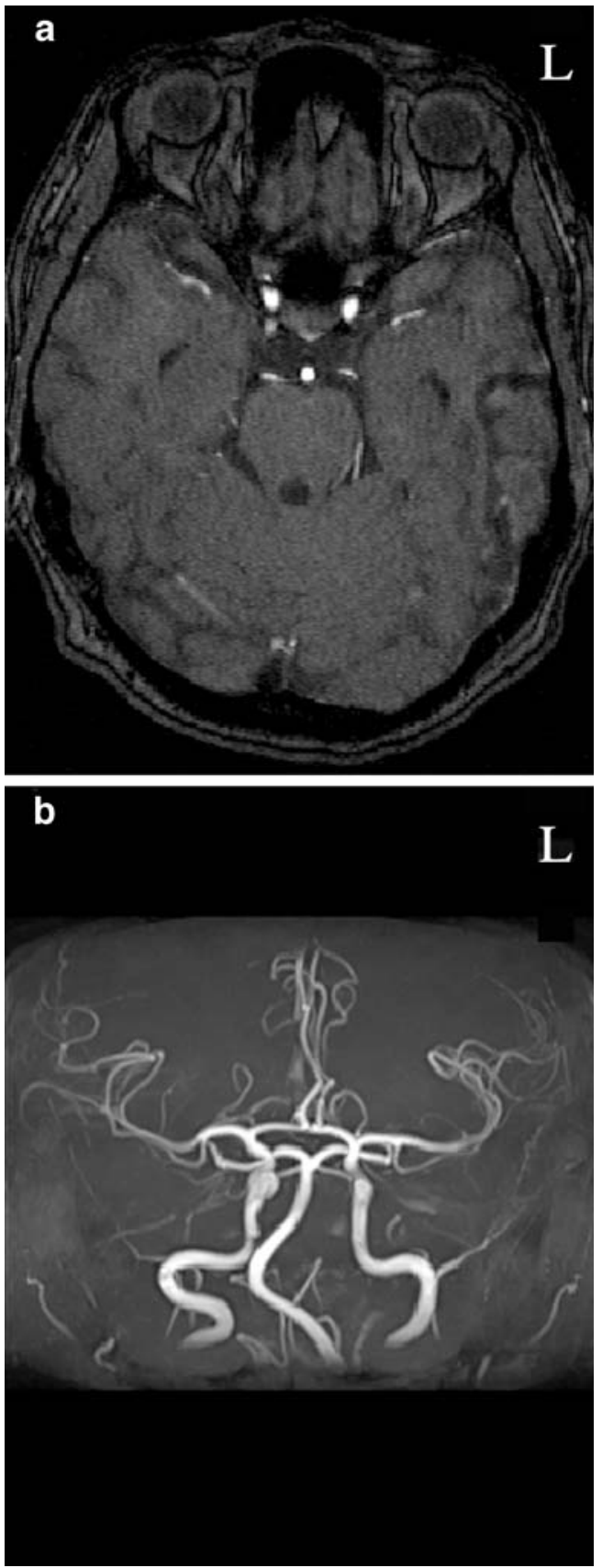

Fig. 2 a, b: Neither the source images nor the MIP-projection of the first MRA 4 months after the haemorrhage show abnormalities suspicious of a vascular malformation. The discrete T1-hyperintense rim at the border zone of the haemorrhage was interpreted as a residuum of the haemorrhage itself. Imaging parameters: Siemens Magneton TRIO, TR: $22.0 \mathrm{~ms}$, TE: $3.7 \mathrm{~ms}$, BW: 180.0, FOV: $150 \times$ $200 \mathrm{~mm}$, MATRIX: $202 \times 384$. Flash $3 \mathrm{D} 1 \mathrm{r}$ ts $/ 18$. Field of view [FOV] $25.0 \times 25.0 \mathrm{~cm}$, data matrix $256 \times 256$, repetition time [TR] $1.3 \mathrm{~s}$, echo time [TE] $10 \mathrm{~ms}$ field of view [FOV] $25.0 \times 25.0 \mathrm{~cm}$, data matrix $256 \times 256$, repetition time [TR] $1.3 \mathrm{~s}$, echo time [TE] $10 \mathrm{~ms}$ 

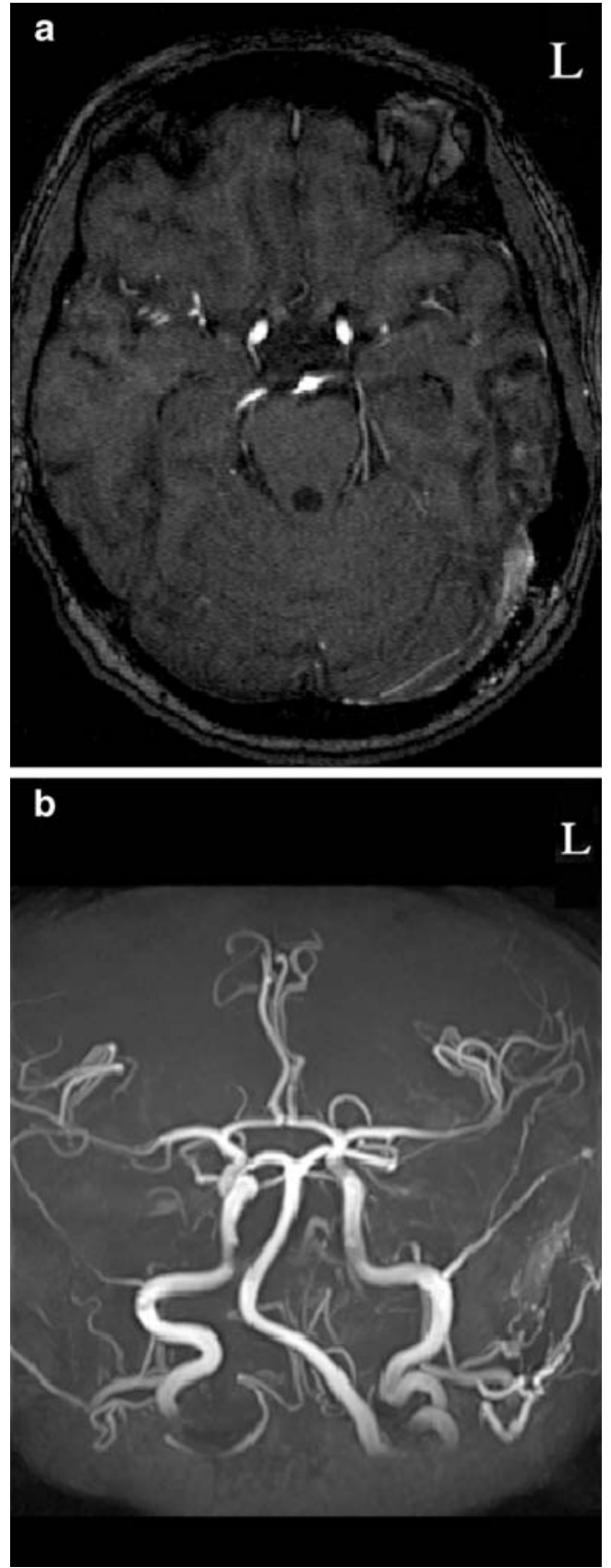

Fig. 3 a, b: Follow-up MRA eight months after the haemorrhage. The source images show a spontaneous hyperintense transverse sinus on the left side. The MIP-projection shows aberrant serpingious vessels projecting to the left temporo-occipital region. Imaging parameters: see legend for Fig. 2

Conflict of interest statement We declare that we have no conflict of interest.

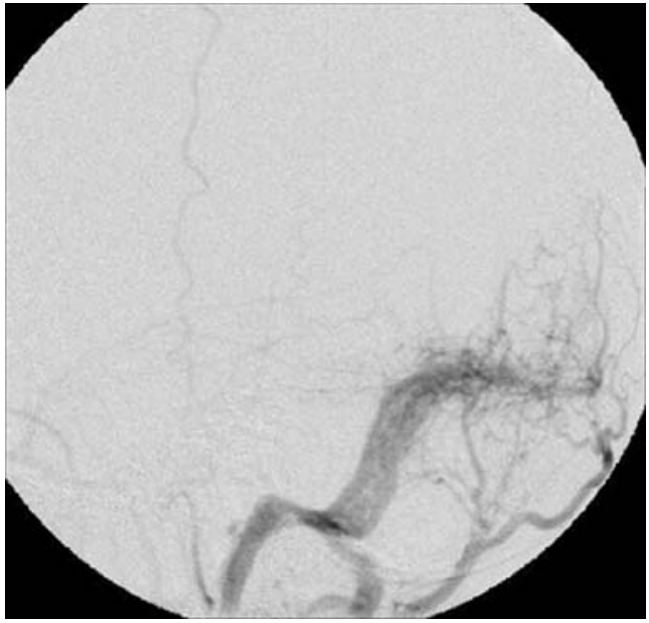

Fig. 4 DSA via the left external carotid artery nine months after the haemorrhage confirmed the diagnosis of a DAVF. Arterial filling was mainly via the left occipital artery, draining into a large transverse sinus. Drainage into superficial cortical veins was not observed (Cognard type IIa [11])

Open Access This article is distributed under the terms of the Creative Commons Attribution Noncommercial License which permits any noncommercial use, distribution, and reproduction in any medium, provided the original author(s) and source are credited.

\section{References}

1. Cognard C, Gobin YP, Pierot L et al (1995) Cerebral dural arteriovenous fistulas: clinical and angiographic correlation with a revised classification of venous drainage. Radiology 194:671-680

2. Noguchi K, Melhem ER, Kanazawa T et al (2004) Intracranial dural arteriovenous fistulas: evaluation with combined $3 \mathrm{D}$ time-of-flight MR angiography and MR digital subtraction angiography. AJR Am J Roentgenol 182:183-190

3. Kwon BJ, Han MH, Kang HS et al (2005) MR imaging of intracranial dural arteriovenous fistulas: relations with venous drainage patterns. AJNR Am J Neuroradiol 26:2500-2507

4. Meckel S, Meyer M, San Millan Ruiz D et al (2007) MR angiography of dural arteriovenous fistulas: diagnosis and followup after treatment using a time-resolved $3 \mathrm{D}$ contrast enhanced technique. AJNR Am J Neuroradiol 28:877-884

5. Luciani A, Houdart E, Mounayer C et al (2001) Spontaneous closure of dural arteriovenous fistulas: report of three cases and review of the literature. AJNR Am J Neuroradiol 22:992-996

6. Kutluk K, Schumacher M, Mironov A (1991) The role of sinus thrombosis in occipital dural arteriovenous malformations - development and spontaneous closure. Neurochirurgia (Stuttg) 34:144-147

7. Luciani A, Houdart E, Mounayer C et al (2001) Spontaneous closure of dural arteriovenous fistulas: report of three cases and review of the literature. AJNR Am J Neuroradiol 22:992-996

8. Rohr J, Gauthier G (1985) Spontaneous regression of a posterior fossa dural arteriovenous malformation. Rev Neurol (Paris) $141: 240-244$ 